\title{
Effects of turbulent eddies and Langmuir circulations on scalar transfer in a sheared wind-driven liquid flow
}

\author{
$\operatorname{AUTHOR}(\mathrm{S}):$ \\ Takagaki, Naohisa; Kurose, Ryoichi; Tsujimoto, \\ Yuta; Komori, Satoru; Takahashi, Keiko
}

\section{CITATION:}

Takagaki, Naohisa ...[et al]. Effects of turbulent eddies and Langmuir circulations on scalar transfer in a sheared wind-driven liquid flow. Physics of Fluids 2015, 27(1): 016603.

\section{ISSUE DATE: \\ 2015-01-14}

URL:

http://hdl.handle.net/2433/196861

\section{RIGHT:}

(c) 2015 American Institute of Physics. This article may be downloaded for personal use only. Any other use requires prior permission of the author and the American Institute of Physics. 


\title{
Effects of turbulent eddies and Langmuir circulations on scalar transfer in a sheared wind-driven liquid flow
}

\author{
Naohisa Takagaki, ${ }^{1}$ Ryoichi Kurose,,${ }^{1, a)}$ Yuta Tsujimoto, ${ }^{1}$ Satoru Komori, ${ }^{1}$ \\ and Keiko Takahashi ${ }^{2}$ \\ ${ }^{1}$ Department of Mechanical Engineering and Science and Advanced Research Institute \\ of Fluid Science and Engineering, Kyoto University, Kyoto 615-8140, Japan \\ ${ }^{2}$ Center for Earth Information Science and Technology (CEIST), Japan Agency \\ for Marine-Earth Science and Technology (JAMSTEC), Yokohama 236-0001, Japan
}

(Received 3 August 2014; accepted 30 December 2014; published online 14 January 2015)

\begin{abstract}
The effects of turbulent eddies and Langmuir circulations in liquid flow on scalar transfer across a sheared wind-driven gas-liquid interface are investigated by means of a direct numerical simulation of a gas-liquid two-phase turbulent flow with a wind-driven nonbreaking wavy interface. The wind-driven wavy gas-liquid interface is captured using an arbitrary Lagrangian-Eulerian method with boundary-fitted coordinates on moving grids. The results show that Langmuir circulations are generated on the liquid side below the sheared wind-driven gas-liquid interface. The marker particles on the gas-liquid interface, the turbulent eddies in the form of streamwise vortices on the liquid side (i.e., the typical horseshoe vortices associated with bursting motions), and the low scalar flux lines on the gas-liquid interface induced by the turbulent eddies on the liquid side tend to locally concentrate in the regions along the downward flows caused by the Langmuir circulations. It is suggested that the turbulent eddies on the liquid side mainly control the scalar transfer across the sheared wind-driven gas-liquid interface, and the effect of the Langmuir circulations is relatively small. @ 2015 AIP Publishing LLC. [http://dx.doi.org/10.1063/1.4905845]
\end{abstract}

\section{INTRODUCTION}

Heat and mass transfer phenomena across gas-liquid interfaces are encountered in many geophysical and industrial processes, and it is therefore of great importance to clarify such scalar transfer mechanism and model them in order to precisely predict climate and weather and to adequately operate industrial plants. To clarify the scalar transfer mechanism and to evaluate precisely the level of scalar transfer across the wind-driven wavy gas-liquid interface, researchers have conducted field observations (e.g., Wanninkhof and McGillis; ${ }^{1}$ McGillis et al.; ${ }^{2}$ McNeil and D'Asaro ${ }^{3}$ ), laboratory experiments using a wind-wave tank (e.g., Jähne et al. ${ }^{4-6}$ Wanninkhof; ${ }^{7}$ Komori et al. $;^{8,9}$ Iwano et al. ${ }^{10}$ ), and direct numerical simulations (DNSs) of gas-liquid two-phase turbulent flows with wind-driven wavy interfaces (e.g., Kunugi et al. ${ }^{11}$ Lakehal et al. $;{ }^{12-14}$ Banerjee et al. $;^{15}$ Banerjee; ${ }^{16}$ Komori et al. $\left.{ }^{17}\right)$. Komori et al. ${ }^{8,9,17}$ reported that the scalar transfer is enhanced by surface-renewal turbulent eddies in the form of streamwise vortices generated on the liquid side beneath the interfaces. Moreover, Langmuir circulations, which are longitudinal vortices aligned with the wind and considered to be induced by the interaction of Stokes drift and shear (Craik and Leibovich; ${ }^{18}$ Leibovich; $;{ }^{19}$ Thorpe ${ }^{20}$ ), are also thought to play an important role for scalar transfer across the gas-liquid interface (e.g., McWilliams et al. ${ }^{21}$ Sullivan and McWilliams, ${ }^{22}$ Garbe et $a .^{23}$ ). Although such Langmuir circulations are often seen in the ocean and lakes, Melville et al. ${ }^{24}$ found through the laboratory experiments with wind wave tank that small-scale Langmuir circulations exist. Very recently, Tsai et al. ${ }^{25}$ performed a DNS of a turbulent liquid flow beneath

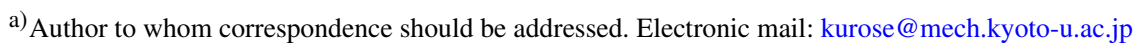


nonbreaking gravity-capillary waves in which simplified driving shear stress and surface-normal pressure on the liquid surface are given, that is, the coupling between the gas and liquid flows is neglected. They concluded that the scalar transfer across the gas-liquid interface is controlled both by the turbulent eddies and the Langmuir circulations. However, each contribution of turbulent eddies and Langmuir circulations on the liquid-side scalar transfer coefficient has not been fully clarified yet.

The purpose of this study is therefore to investigate the effects of turbulent eddies and Langmuir circulations on scalar transfer across a sheared wind-driven gas-liquid interface by a DNS of a gas-liquid two-phase turbulent flow with a wind-driven nonbreaking wavy interface. In order to exactly evaluate the relationship between the turbulent eddies and Langmuir circulations and their effects on the scalar transfer in realistic wind-driven turbulence, the development of the wind waves from a stationary state is strictly simulated by coupling the gas and liquid flows, as in Komori et al. ${ }^{17}$

\section{NUMERICAL SIMULATION}

The wind-driven wavy gas-liquid interface was captured using an arbitrary Lagrangian-Eulerian (ALE) method with boundary-fitted coordinates (BFC) on moving grids (Komori et al.; ${ }^{17,26}$ Fulgosi et al. ${ }^{27}$ Lin et al. ${ }^{28}$ ). The numerical procedure of the DNS used here was the same as in Komori et al. ${ }^{17}$ but to capture the Langmuir circulations, the computational domain was set to be larger than that in Komori et al. ${ }^{17}$

The non-dimensional governing equations for an incompressible Newtonian fluid flow with scalar transfer are given by the equation of continuity, Navier-Stokes (N-S) equation, and transport equation of passive scalar using the Einstein summation convention

$$
\begin{aligned}
& \frac{\partial U_{i}}{\partial x_{i}}=0, \\
& \frac{\partial U_{i}}{\partial t}+U_{j} \frac{\partial U_{i}}{\partial x_{j}}=-\frac{\partial p}{\partial x_{i}}+\frac{1}{R e} \frac{\partial^{2} U_{i}}{\partial x_{j} \partial x_{j}}+\frac{1}{F r} \delta_{i 3}, \\
& \frac{\partial C}{\partial t}+U_{j} \frac{\partial C}{\partial x_{j}}=\frac{1}{R e \cdot S c} \frac{\partial^{2} C}{\partial x_{j} \partial x_{j}},
\end{aligned}
$$

where $U_{\mathrm{i}}$ is the $i$ th component of the velocity vector $(i=1,2$, and 3 denote the streamwise, spanwise, and vertical directions, respectively), $p$ the pressure, $\delta_{\mathrm{ij}}$ the Kronecker's delta, and $C$ the passive scalar. The non-dimensional parameters, $R e, S c$, and $F r$ are defined as

$$
R e=\frac{U_{0} L_{0}}{v}, S c=\frac{v}{D}, F r=\frac{U_{0}^{2}}{g L_{0}},
$$

where $L_{0}$ and $U_{0}$ are the reference length and velocity, $v$ is the kinematic viscosity, $D$ the molecular diffusivity of scalar, and $g$ the acceleration of gravity. On the gas-liquid interface, two boundary conditions should be satisfied. One is the kinematic boundary condition that describes the Lagrangian behavior of the fluid particle on the free surface, and the other is the dynamic boundary condition which is determined from the balance of stresses acting on the interface in the normal and tangential directions.

The computational domain and numerical grids for the computations of flows in the gas and liquid are shown in Figure 1. The size of the computational domain was $6 \delta \times 4.2 \delta \times 3 \delta$ in the streamwise $(x)$, spanwise $(y)$, and vertical $(z)$ directions. The origin $(x=y=z=0)$ was located at the height of $2 \delta$ from the bottom, and the initial flat gas-liquid interface which divides the two-phase flow between upper gas and lower liquid streams was placed on the plane of $z=0$. The grid points used in the streamwise $(x)$, spanwise $(y)$, and vertical $(z)$ directions were $300 \times 210 \times 90$ on the gas side and $300 \times 210 \times 180$ on the liquid side, respectively. The grid spacing was equidistant in the streamwise $(x)$ and spanwise $(y)$ directions, and to get high resolution, the nonuniform meshes clustered in the gas-liquid-interface region were used in the vertical $(z)$ direction. Periodic boundary conditions were applied in the streamwise $(x)$ and spanwise $(y)$ directions, and the slip boundary condition was applied at the top and bottom boundaries. For the initial conditions of flow field, a 


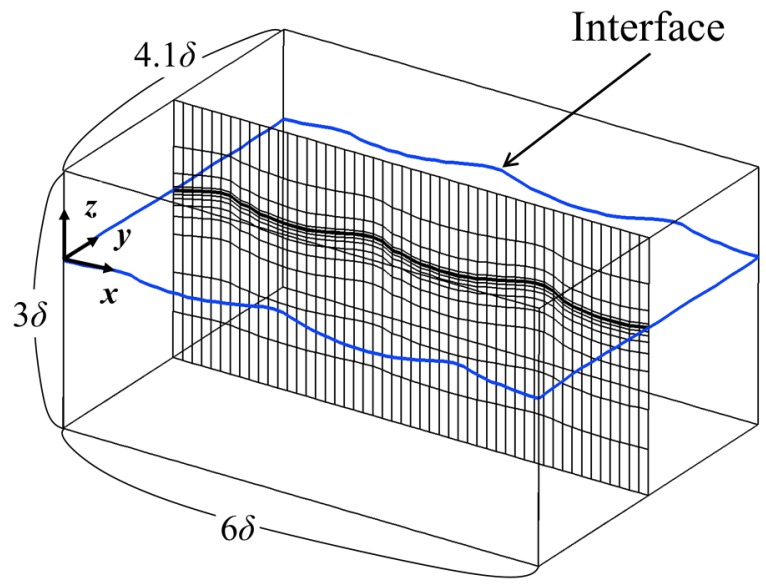

FIG. 1. Computational domain and grids depicted coarsely. The arrow shows an instantaneous location of the gas-liquid interface.

fully developed wall turbulent flow and a quiescent flow were imposed on the gas and liquid sides of the initial flat interface, respectively. For the computation of scalar transfer on the liquid side, the boundary conditions for the passive scalar at the gas-liquid interface and the bottom boundary were given by $C=1.0$ and Neumann condition, respectively. The marker and cell (MAC) method $\left(\right.$ Harlow and $\mathrm{Welch}^{29}$ ) was used to solve the Navier-Stokes equation. In order to induce a realistic deformation at the gas-liquid interface, a fully developed wall turbulence for an initial uniform velocity of $U_{\infty, \text { ini }}=5.8 \mathrm{~m} / \mathrm{s}$ and an initial friction velocity of $u_{* \text {,ini }}=0.24 \mathrm{~m} / \mathrm{s}$ were given on the gas side over a flat quiescent liquid. The gas flow was driven by a pressure gradient imposed in the streamwise direction. The value of the Reynolds number based on $U_{\infty}$,ini and height of the computational domain on the gas side $\left(\delta=2.5 \times 10^{-2} \mathrm{~m}\right), R e_{\text {ini }}$, was 9670 and $R e_{\text {ini }}$ based on $u_{* \text {,ini }}$ and $\delta$ was 400 . Also, the values of two non-dimensional times, one based on $U_{\infty}$,ini and $\delta$ and the other on $u_{* \text {,ini }}$ and $\delta$, were 232 and 9.6, respectively. The density ratio of the gas and liquid was 830 , which corresponds to the value for the air-water two-phase flow at about $20^{\circ} \mathrm{C}$. The liquid-side Schmidt number $S c\left(=v_{\mathrm{L}} / D_{\mathrm{L}}\right.$, where $\nu_{\mathrm{L}}$ and $D_{\mathrm{L}}$ are the kinematic viscosity and molecular diffusivity of liquid, respectively) was 1.0. The central processing unit (CPU) time was about $19200 \mathrm{~h}$ for 4800000 steps (12 s) on the super computer NEC:SX-9.

\section{RESULTS AND DISCUSSION}

\section{A. Velocity field}

Figure 2 shows the instantaneous configuration of the gas-liquid interface at $t=6.0$ and $12.0 \mathrm{~s}$. Wind waves were seen to develop and evolve micro-breaking waves (i.e., ripples) on the leeward side of the wind waves. The same wave shape was observed in our previous experiment and prediction and the details are described in Komori et al. ${ }^{17}$ The conditions of gas flow and wind waves are listed in Table I. Here, the uniform velocity, $U_{\infty}$, was defined as the velocity on the upper wall of the computational domain. Wind speeds at $10-\mathrm{m}$ height above sea surface, $U_{10}$, were estimated using the logarithmic profile

$$
U_{10}-U_{S U R F}=\frac{u_{a} *}{\kappa} \ln \frac{10}{z_{0}}
$$

where $U_{\text {SURF }}$ is the surface current, $\kappa$ the von Karman constant, and $z_{0}$ roughness length. Here, $U_{\text {SURF }}$ is estimated in the same manner as Komori et al. ${ }^{17}$ Each wind wave was determined by applying the zero-up cross method to the spatial fluctuation of the water level, and the significant wave height, $H_{\mathrm{S}}$, and significant wave length, $L_{\mathrm{S}}$, were defined as the mean wave height and length for the largest one-third waves. The phase speed of the significant wind-waves, $C_{\mathrm{p}}$, was measured by analyzing 


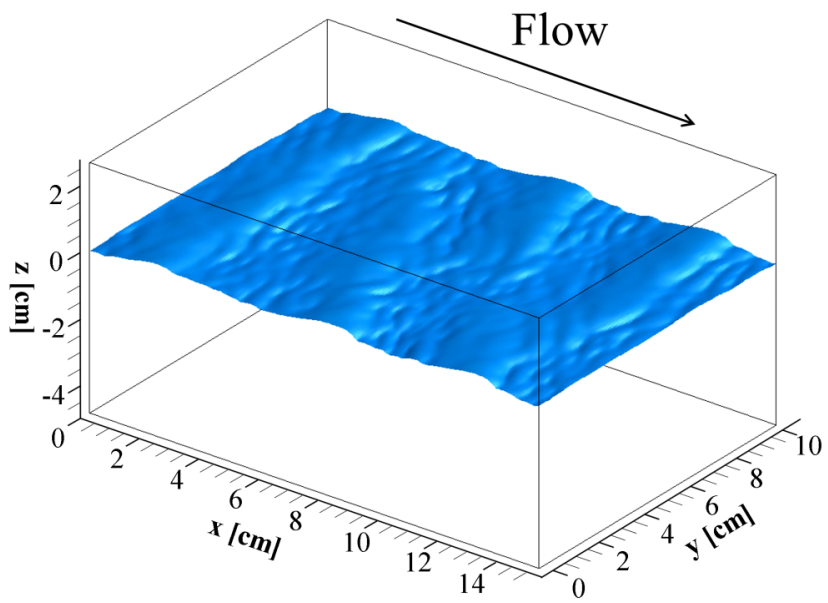

(a) $t=6.0 \mathrm{~s}$

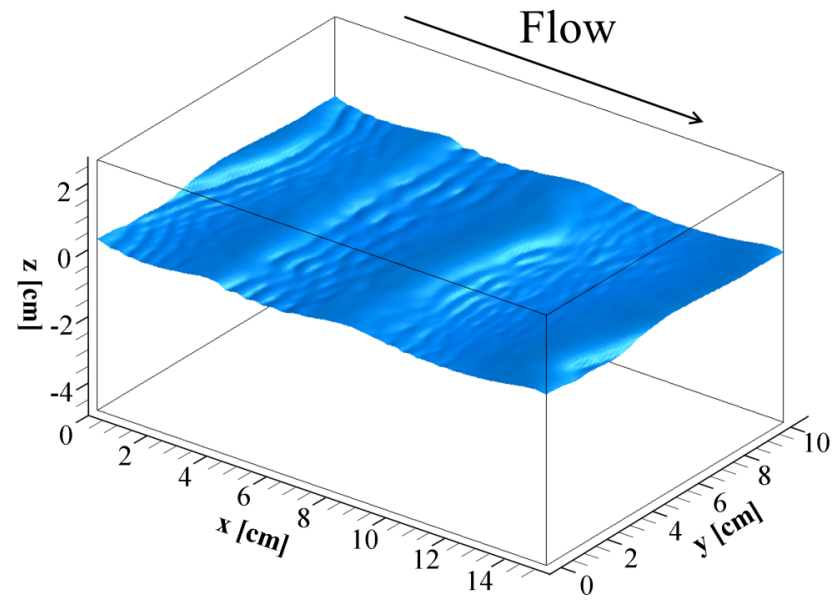

(b) $t=12.0 \mathrm{~s}$

FIG. 2. Instantaneous configuration of predicted gas-liquid interface at (a) $t=6.0 \mathrm{~s}$ and (b) $t=12.0 \mathrm{~s}$. Nondimensional lengths based on friction velocity $u_{\mathrm{w}} *$ and liquid-side kinematic viscosity $v_{\mathrm{L}}$ for $x=1 \mathrm{~cm}$ are 100 and 92 at $t=6.0$ and $12.0 \mathrm{~s}$, respectively.

the propagation of the significant wind-waves. Although the predicted significant wind-waves were Doppler shifted by the surface current, the statistical properties of the wind-waves were confirmed to be almost consistent with our laboratory data (Takagaki et al. ${ }^{30}$ ) and the dispersed relation for the capitally gravity wave and Toba's $3 / 2$ law $\left(\mathrm{Toba}^{31}\right)$.

TABLE I. Predicted characteristics of gas flow, wind waves, and Langmuir circulations. $t$ : elapsed time, $U_{\infty}$ : free stream wind speed, $u_{\mathrm{a}}{ }^{*}$ : gas-side friction velocity, $U_{10}$ : wind speed at $10-\mathrm{m}$ height, $U_{\mathrm{SURF}}$ : surface current, $H_{\mathrm{S}}$ : significant wave height, $L_{\mathrm{S}}$ : significant wave length, $C_{\mathrm{P}}$ : phase speed of significant wind waves, $D_{\text {Langmuir: }}$ spacing of liquid-side downward flow, $\lambda_{\mathrm{LS}}$ : secondary-peak spacing on the probability density function of streak spacing of the scalar flux on the liquid surface (see Fig. 9), La: Langmuir number, $k$ : normalized transverse wavenumber of Langmuir circulations based on the spacing between the downward flows.

\begin{tabular}{rccccccccccc}
\hline \hline & $\begin{array}{c}U_{\infty} \\
t(\mathrm{~s})\end{array}$ & $\begin{array}{c}u_{\mathrm{a}}{ }^{*} \\
(\mathrm{~m} / \mathrm{s})\end{array}$ & $\begin{array}{c}U_{10} \\
(\mathrm{~m} / \mathrm{s})\end{array}$ & $\begin{array}{c}U_{\text {SURF }} \\
(\mathrm{m} / \mathrm{s})\end{array}$ & $H_{\mathrm{S}}(\mathrm{m})$ & $L_{\mathrm{S}}(\mathrm{m})$ & $\begin{array}{c}C_{\mathrm{P}} \\
(\mathrm{m} / \mathrm{s})\end{array}$ & $\begin{array}{c}D_{\text {Langmuir }} \\
(\mathrm{m})\end{array}$ & $\begin{array}{c}\lambda_{\mathrm{LS}} \\
(\mathrm{m})\end{array}$ & $L a(-)$ & $k(-)$ \\
\hline 6.0 & 4.30 & 0.277 & 8.59 & 0.0813 & 0.00247 & 0.0365 & 0.325 & 0.0292 & $\ldots$ & 0.00325 & 1.25 \\
12.0 & 3.48 & 0.256 & 7.42 & 0.0737 & 0.00386 & 0.0501 & 0.351 & 0.0468 & 0.0406 & 0.00587 & 1.07 \\
\hline \hline
\end{tabular}




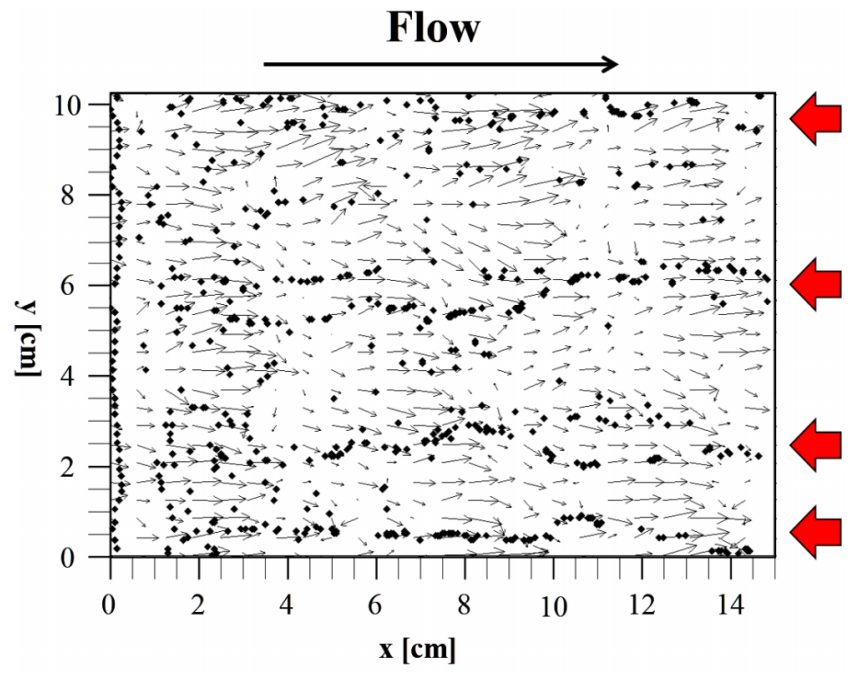

(a) $t=6.0 \mathrm{~s}$

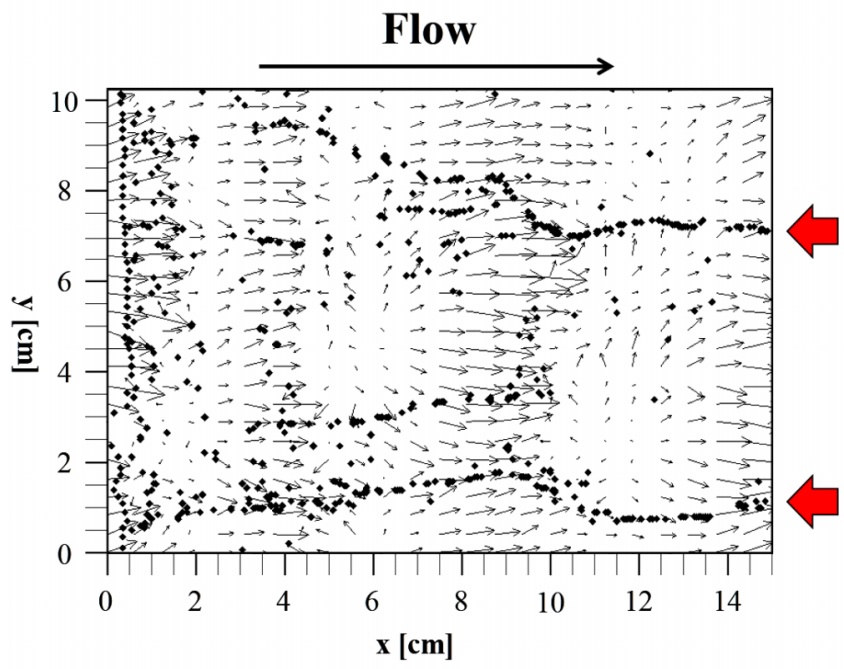

(b) $t=12.0 \mathrm{~s}$

FIG. 3. Instantaneous distributions of marker particles (bold circles) and velocity vectors on the gas-liquid interface at (a) $t=6.0 \mathrm{~s}$ and (b) $t=12.0 \mathrm{~s}$. Arrows show streak locations. Nondimensional lengths are as given in Fig. 2 .

Figure 3 shows the instantaneous distributions of marker particles and velocity vectors on the gas-liquid interface at $t=6.0$ and $12.0 \mathrm{~s}$. Here, the marker particles are initially aligned in the spanwise direction at equal distances along the line $x=0 \mathrm{~m}$ and $z=0 \mathrm{~m}$ and tracked along the interface without imposing the periodic boundary conditions. The marker particles tended to form fewer streaks with time, and arrows added on the figure clearly indicate the locations of the streaks.

The streaks of the marker particles are considered to be caused by the streamwise vortices, namely, turbulent eddies and/or Langmuir circulations, generated on the liquid side below the wind-driven gas-liquid interface (Komori et al.;9,17 Tsai et al. ${ }^{25}$ ). In order to investigate the liquidside turbulent structure, we visualized the vortical structure using instantaneous iso-surface of the second invariant $Q$ defined as

$$
Q=\frac{1}{2}\left\{\left(\frac{\partial u_{i}}{\partial x_{i}}\right)^{2}-\frac{\partial u_{i}}{\partial x_{j}} \frac{\partial u_{j}}{\partial x_{i}}\right\},
$$


where $u_{\mathrm{i}}$ is the $i$ th component of the velocity vector. A positive $Q(Q>0)$ means the presence of vortices and higher $Q$ corresponds to stronger vortices. Figure 4 shows the instantaneous iso-surfaces with high positive values of $Q$ at $t=6.0$ and $12.0 \mathrm{~s}$, where the iso-surfaces on the liquid side are inscribed in the bottom view. The typical horseshoe vortices associated with bursting motions which are similar to those over the flat rigid wall are observable. In addition, these typical horseshoe vortices locally concentrate and shape streamwise lines in the same locations as

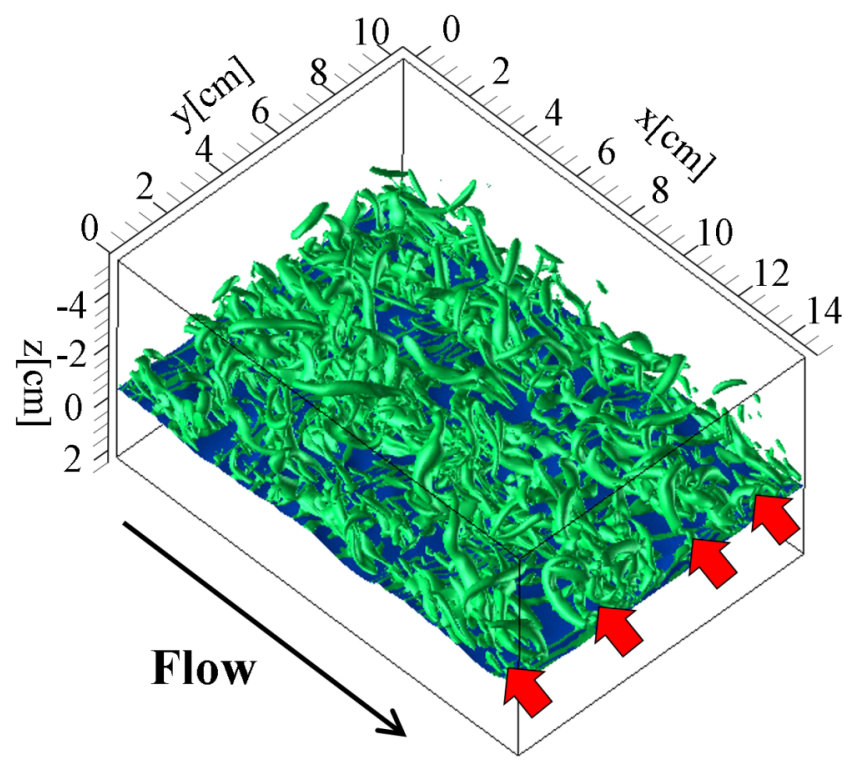

(a) $t=6.0 \mathrm{~s}$

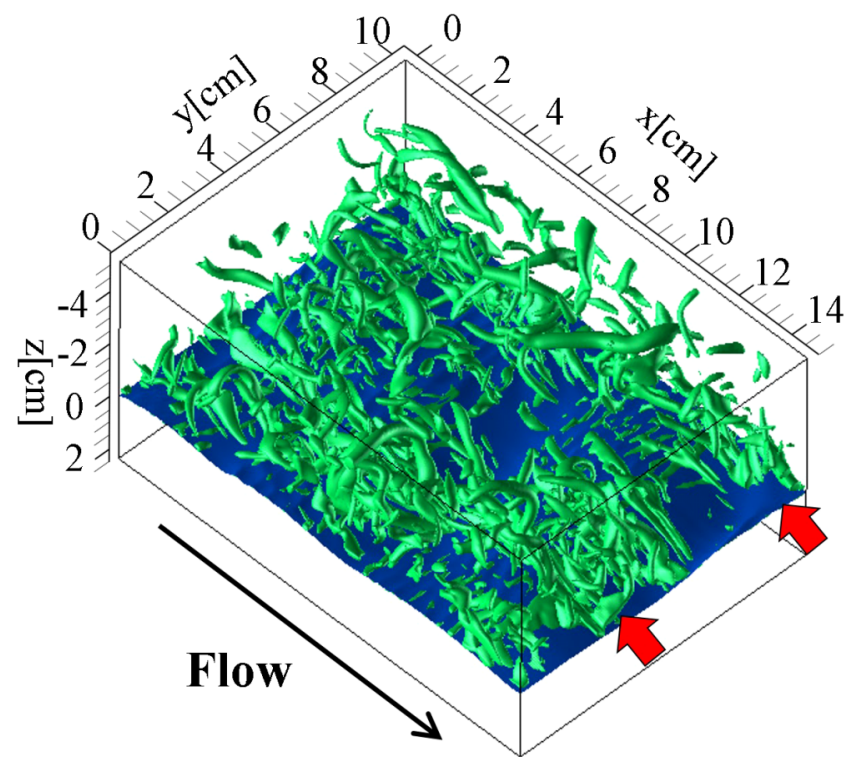

(b) $t=12.0 \mathrm{~s}$

FIG. 4. Instantaneous iso-surfaces of second invariant on the liquid side at (a) $t=6.0 \mathrm{~s}$ and (b) $t=12.0 \mathrm{~s}$ (the value of iso-surface is $128 \mathrm{~s}^{-2}$ ). Arrows show streak locations. Nondimensional lengths are as given in Fig. 2. 
surface streaks made by marker particles (see Figure 3 ). This suggests that there possibly exists a certain fluid motion which forcibly concentrates horseshoe vortices into several streamwise streaks, namely, Langmuir circulations.

Recently, Tsai et $a l .{ }^{25}$ visualized the Langmuir circulations by taking a streamwise-averaging manipulation

$$
\dot{\Phi}=\frac{1}{6 \delta} \int_{0}^{6 \delta} \Phi d x
$$

of the physical variables, $\Phi$, with the turbulent flow fields containing both streamwise vortices and Langmuir circulations to remove the effect of streamwise vortices on the variables. Figure 5
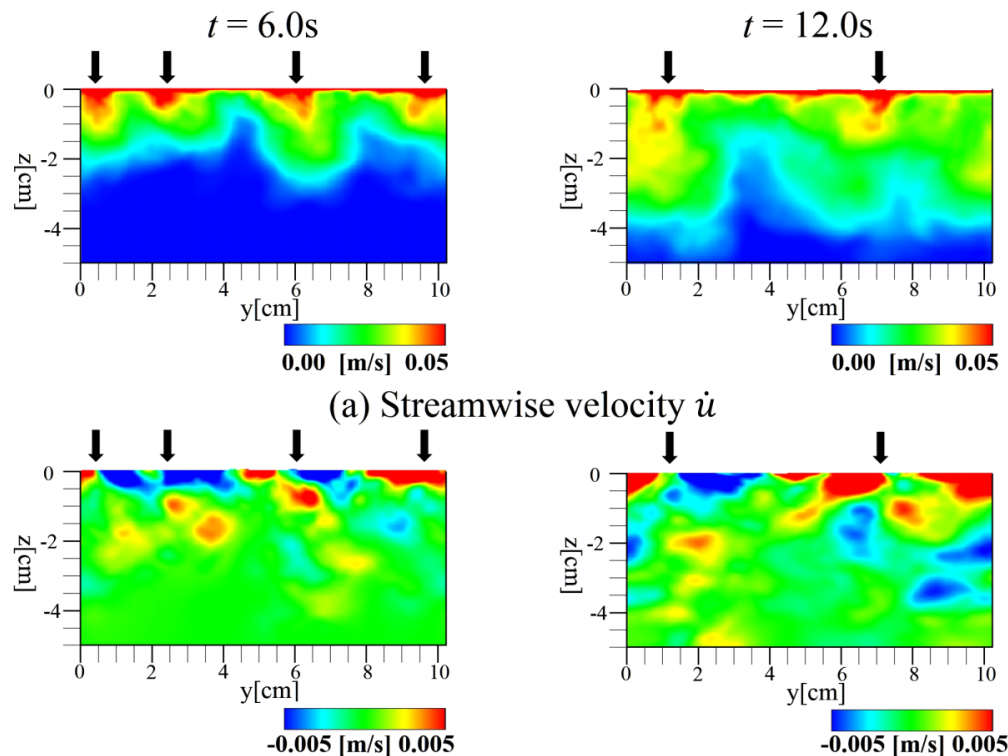

(b) Spanwise velocity $\dot{v}$
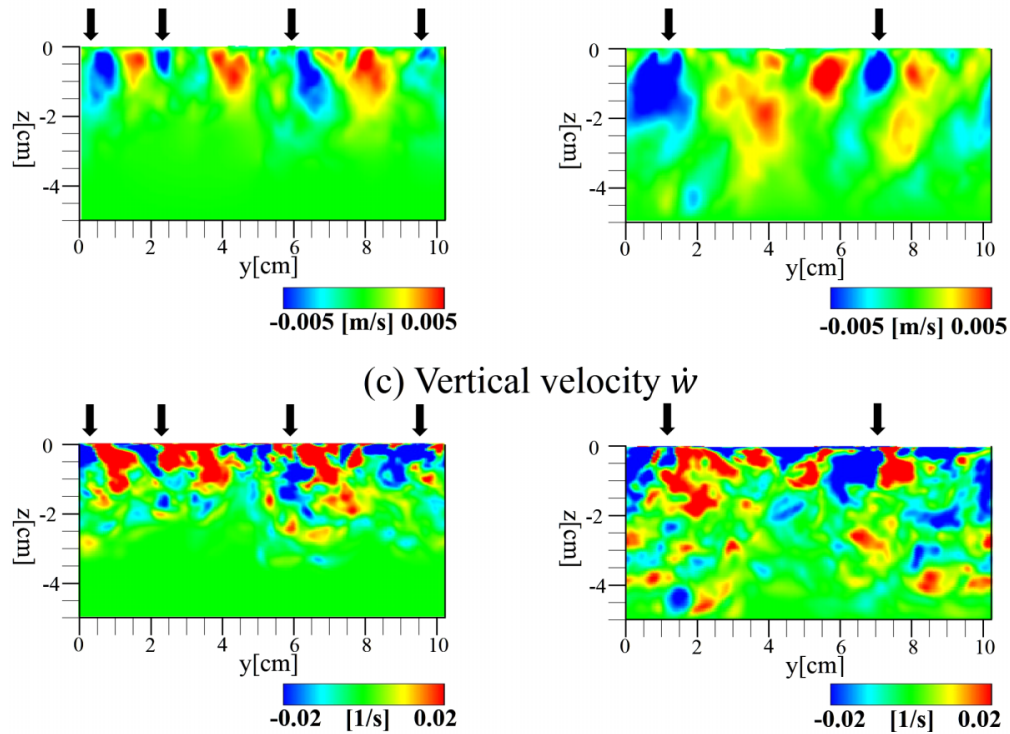

(c) Vertical velocity $\dot{w}$

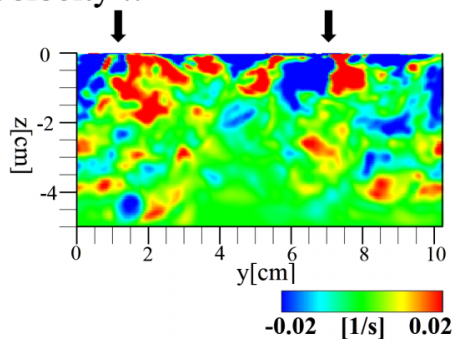

(d) Streamwise vorticity $\dot{r}_{32}$

FIG. 5. Cross-sectional ( $y-z$ plane) distributions of streamwise-averaged variables on the liquid side at $t=6.0 \mathrm{~s}$ (left column) and $t=12.0 \mathrm{~s}$ (right column). Arrows show locations of strong downward flows. Nondimensional lengths are as given in Fig. 2. 
shows the cross-sectional ( $y-z$ plane) distributions of the streamwise-averaged streamwise velocity $\dot{u}$, spanwise velocity $\dot{v}$, vertical velocity $\dot{w}$, and streamwise vorticity $\dot{r}_{32}$ on the liquid side below the gas-liquid interface at $t=6.0$ and $12.0 \mathrm{~s}$. At $t=6.0 \mathrm{~s}$, four solitary parts with strong downstream flow (positive $\dot{u}$ ) just below the gas-liquid interface can be seen and accompany strong downward flow (negative $\dot{v}$ ) and pairs of strong vortices (positive and negative $\dot{r}_{32}$ ) around the strong downstream flow. It was also confirmed that the four solitary parts accompanied fast surface currents. For greater clarification, we added arrows on the strong downward flows. Leibovich ${ }^{19}$ and Thorpe ${ }^{20}$ pointed out that Langmuir circulations accompanied strong streamwise surface currents and downward flows on the liquid side, and these trends correspond well to the present trends on the predicted liquid flow field (see Figure 5). In addition, the number of pairs of strong vortices is clearly less than that of the instantaneous horseshoe vortices (see Figure 5) and decreases with time (see Figure $5, t=6.0$ and $12.0 \mathrm{~s}$ ). Therefore, we concluded that the vortices observed in Figures 4 and 5 are turbulent eddies and Langmuir circulations, respectively.

In order to predict whether the Langmuir circulations emerge or not, Leibovich and Paolucci ${ }^{32}$ proposed a stability diagram based on the relations between inverse Langmuir number, $L a^{-1}$, and normalized transverse wavenumber based on the spacing between the downward flows (see Figure $5(\mathrm{c})), k$. These definitions are as follows:

$$
\begin{gathered}
L a=\left(\frac{4 v_{L, t}{ }^{3} k_{S}{ }^{2}}{\sigma H_{S}{ }^{2} u_{L}^{* 2}}\right)^{1 / 2}, \\
k=\frac{k_{\text {Langmuir }}}{k_{S}},
\end{gathered}
$$

where $v_{\mathrm{L}, \mathrm{t}}$ is the eddy viscosity, $k_{\mathrm{S}}\left(=2 \pi / L_{\mathrm{S}}\right)$ the wavenumber of significant wind-waves, $\sigma$ the significant radian frequency of wind waves, $H_{\mathrm{S}}$ the significant wave height, $u_{\mathrm{L}}{ }^{*}$ the liquid-side frictional velocity, and $k_{\text {Langmuir }}\left(=2 \pi / L_{\text {Langmuir }}\right)$ the dimensional wavenumber based on the spacing between downward flows (see Figure 5(c)). Here, $v_{\mathrm{L}, \mathrm{t}}$ is estimated in the same manner as Tsai et al. ${ }^{25}$ The value of $\sigma$ is estimated assuming deep-sea waves, that is, $\sigma=2 \pi C_{\mathrm{p}} / L_{\mathrm{S}}$. According to these definitions, the values for $L a^{-1}$ are 307 and 170 , and for $k$ are 1.25 and 1.07 at $t=6.0$ and $12.0 \mathrm{~s}$, respectively. The values of $L a$ and $k$ are listed in Table I. This certainly supports the appearance of the Langmuir circulations in this stability diagram from present and previous studies (Melville et al. ; $^{24}$ Tsai et al. ${ }^{25}$ Schnieders et al. ${ }^{33}$ ) (see Figure 6).

\section{B. Scalar concentration field}

It is also suggested that these turbulent eddies and/or Langmuir circulations control the scalar transfer across the wind-driven gas-liquid interface (Komori et al. $;^{9,17}$ Tsai et al. ${ }^{25}$ ). In Figure 7, the

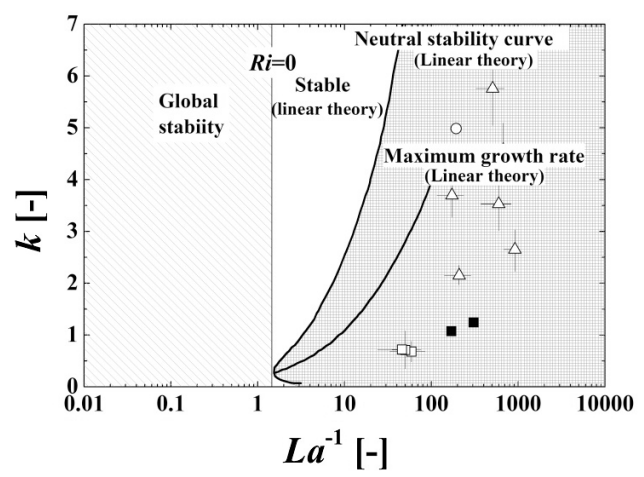

FIG. 6. Neutral stability theory by Leibovich and Paolucci ${ }^{32}$ with previous experimental data; $\mathbf{\square}$, present; $\bigcirc$, Tsai et al. ${ }^{25} \square$, Melville et al. ${ }^{24} \Delta$, Schnieders et al. ${ }^{33}$ 


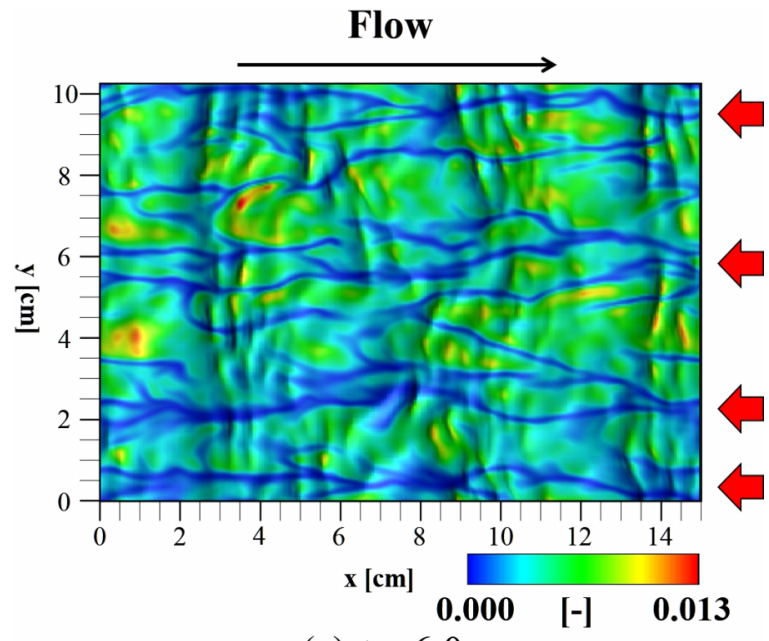

(a) $t=6.0 \mathrm{~s}$

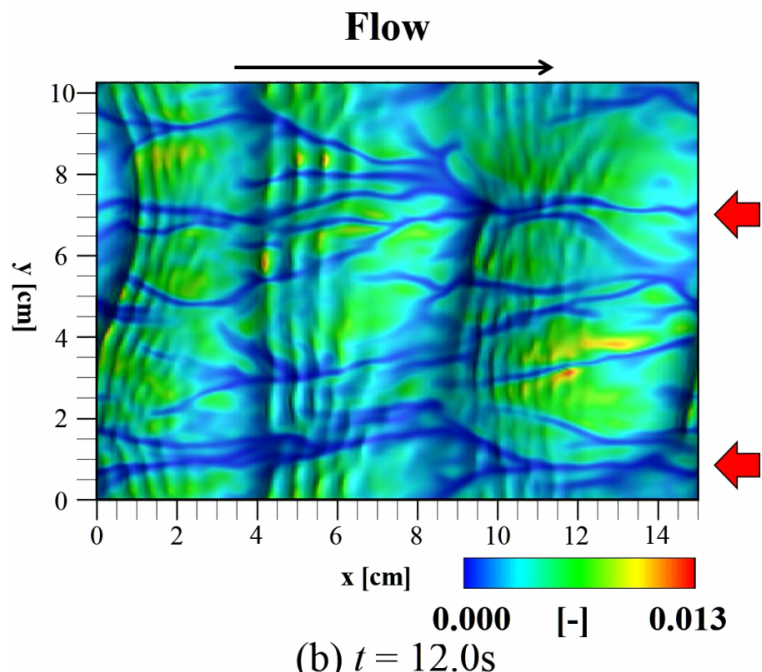

FIG. 7. Distributions of instantaneous scalar flux at (a) $t=6.0 \mathrm{~s}$ and (b) $t=12.0 \mathrm{~s}$. Scalar flux is nondimensionalized by friction velocity $u_{\mathrm{a}}{ }^{*}$ and initial scalar concentration at interface $C_{\mathrm{i}}$. Arrows show streak locations. Nondimensional lengths are as given in Fig. 2.

distributions of the instantaneous local scalar flux on the gas-liquid interface, $F_{\text {local }}$, at $t=6.0$ and $12.0 \mathrm{~s}$ are shown. Here, the local scalar flux on the gas-liquid interface is defined as

$$
F_{\text {local }}=D_{L} \frac{\partial C}{\partial n} .
$$

In addition, Figure 8 shows the cross-sectional ( $y-z$ plane) distributions of the instantaneous scalar concentration on the liquid side below the gas-liquid interface at $t=6.0$ and $12.0 \mathrm{~s}$. The streaky motions of the scalar flux on the gas-liquid interface are observed to be strongly associated with the streamwise vortices related to downward bursting motions appearing beneath the interface. The scalar transfer mechanism across the wind-driven wavy interface is illustrated in Komori et al. ${ }^{17}$ (Figure 24). In summary, a pair of streamwise vortices causes downward bursting motions beneath the streaky regions with both low-scalar flux and high streamwise velocity of the gas-liquid interface, and the so-called "happening-of-peeling" process occurs between the downward bursting motions. Due to this process, the surface layer thickness is reduced, and the gradient of scalar concentration increases and the scalar flux is enhanced. When we see the time changes of the instantaneous local scalar flux on the gas-liquid interface and the instantaneous scalar concentration 

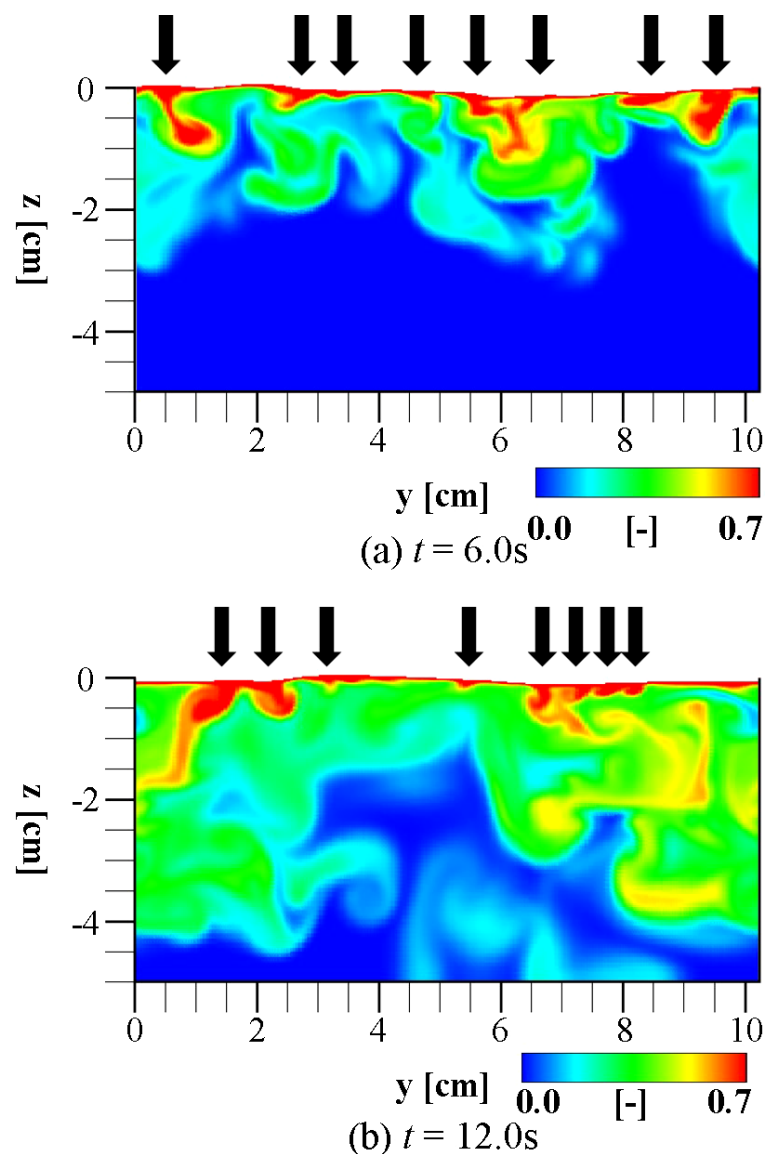

FIG. 8. Cross-sectional ( $y-z$ plane) distributions of instantaneous scalar concentration at $x=3 \delta$ on the liquid side at (a) $t=6.0 \mathrm{~s}$ and (b) $t=12.0 \mathrm{~s}$. Scalar concentration is nondimensionalized by initial scalar concentration at interface $C_{\mathrm{i}}$. Arrows show locations of strong downward flows. Nondimensional lengths are as given in Fig. 2.

on the liquid side in Figures 7 and 8, there seems to be high concentration regions undergoing peeling at $t=12.0 \mathrm{~s}$ rather than at $t=6.0 \mathrm{~s}$.

To investigate the reason why such regions concentrate, we quantitatively evaluated the spacing between low-scalar flux streaks on the gas-liquid interface, $\lambda_{\mathrm{ST}}$, in Figure 7. Figure 9 shows the probability density functions of the normalized spacing between low-scalar flux streaks, $\lambda_{\mathrm{ST}}{ }^{+}$, at $t=6.0$ and $12.0 \mathrm{~s}$, where $\lambda_{\mathrm{ST}}$ is normalized by the friction velocity on the liquid side $u_{\mathrm{L}}{ }^{*}$ and kinematic viscosity on the liquid side $v_{\mathrm{L}}$. The spacing between low-scalar flux streaks, $\lambda_{\mathrm{ST}}{ }^{+}$, almost takes the values ranging from 100 to 200 . Generally, the low-speed wall turbulence streaks develop on the wall, and the spacing between low-speed streaks is known to be about 100 (see Smith and Metzler $^{34}$ ). Considering this presently predicted spacing between low-scalar flux streaks, the streaky structure for the low-scalar flux regions on the gas-liquid interface is induced by the streamwise vortices developing below the gas-liquid interface. Moreover, the spacing between low-scalar flux streaks, $\lambda_{\mathrm{ST}^{+}}{ }^{+}$, is also found to have values in the region around 400 in the later period at $t=12.0 \mathrm{~s}$, which is considered to be attributed to the Langmuir circulations. Then, we compared presently predicted and previously measured spacing of the Langmuir circulations. The present spacing of the liquid-side downward flow $D_{\text {Langmuir }}$ (see Figure 7 ) and secondary-peak spacing $\lambda_{\text {LS }}$ evaluated from Figure 9 are listed in Table I. From the table, it is found that $D_{\text {Langmuir }}$ is almost same as $\lambda_{\mathrm{LS}}$ at $t=12.0 \mathrm{~s}$, that is, this spacing is really caused by Langmuir circulations. On the other hand, $\lambda_{\mathrm{LS}}$ at $t=6.0 \mathrm{~s}$ cannot be estimated here because of the difficulty of separation of $\lambda_{\mathrm{LS}}$ from the probability density function of $\lambda_{\mathrm{ST}}$ (see Figure 9). The previously measured spacing $\lambda_{\mathrm{LS}}{ }^{+}$normalized by the 


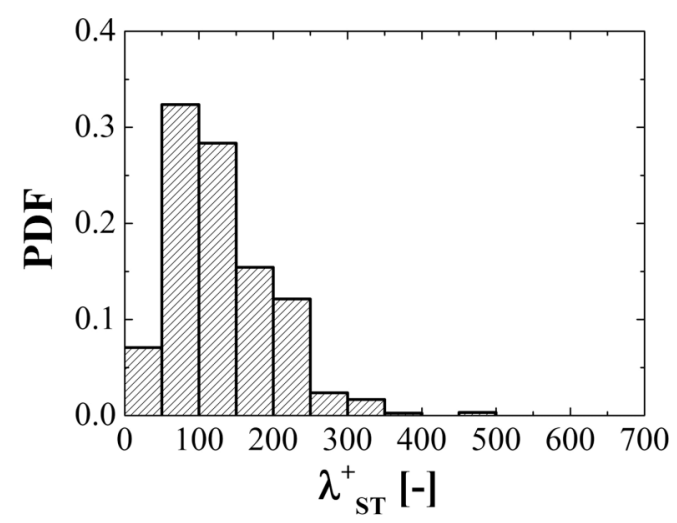

(a) $t=6.0 \mathrm{~s}$

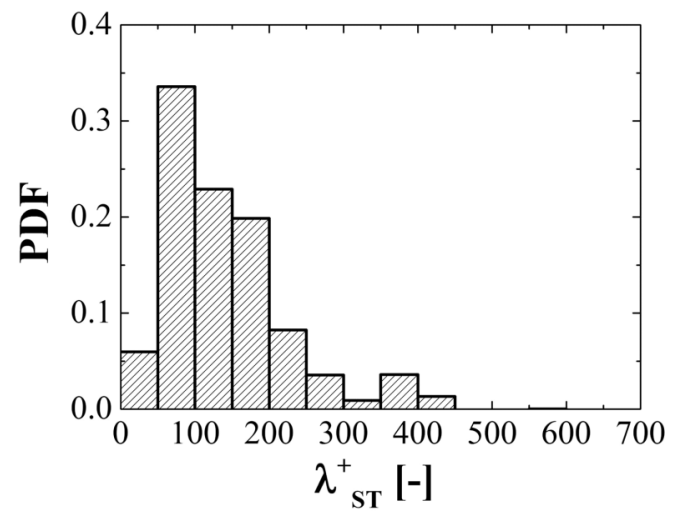

(b) $t=12.0 \mathrm{~s}$

FIG. 9. Probability density function of spacing between low-scalar flux streaks on the interface at (a) $t=6.0 \mathrm{~s}$ and (b) $t=12.0 \mathrm{~s}$.

liquid-side friction velocity $u_{w}{ }^{*}$ and liquid-side viscosity (Melville et al., ${ }^{24}$ Table I) ranged with 260-290 at $u_{a}{ }^{*}=0.1-0.22 \mathrm{~m} / \mathrm{s}$, using the empirical relation (Komori et al. ${ }^{8}$ )

$$
u_{a}^{*}=0.02 U_{\infty}^{1.5},
$$

and the relation

$$
\tau=\rho_{a} u_{a}^{* 2}=\rho_{w} u_{w}^{* 2} .
$$

The previously measured $\lambda_{\mathrm{LS}}{ }^{+}$(Melville et $a{ }^{24}{ }^{24}$ ) are larger than the spacing between low-speed streaks known to be about 100 (Smith and $\mathrm{Metzler}^{34}$ ), and this trend is similar to the presently predicted $\lambda_{\mathrm{LS}}{ }^{+}$of 375 at $u_{a}{ }^{*}=0.25 \mathrm{~m} / \mathrm{s}$.

It is uncertain as to how the turbulent eddies and/or Langmuir circulations affect the gas-liquid scalar transfer. Then, we applied the streamwise-averaging technique (Eq. (7)) to the scalar concentration on the liquid side to visualize the Langmuir circulations. Figure 10 shows the cross-sectional $(y-z$ plane) distributions of the streamwise-averaged scalar concentration on the liquid side below the gas-liquid interface at $t=6.0$ and $12.0 \mathrm{~s}$. Pairs of the streamwise-averaged vortices shown by velocity vectors can be seen, with the number of the streamwise-averaged vortices being less than that of the instantaneous vortices (see Figure 8) and decreasing with time. The trend in the numbers of vortices in the scalar concentration field is the same as those for the flow field. This suggests that the vortices observed in Figures 8 and 10 are turbulent eddies and Langmuir circulations, respectively. 


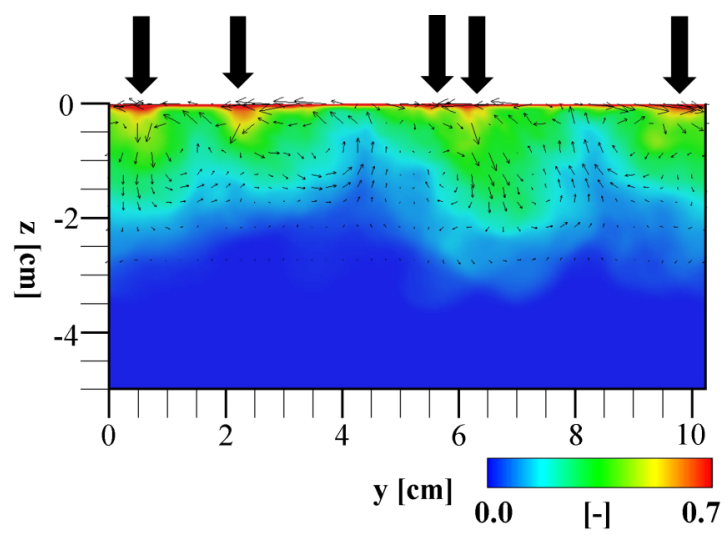

(a) $t=6.0 \mathrm{~s}$

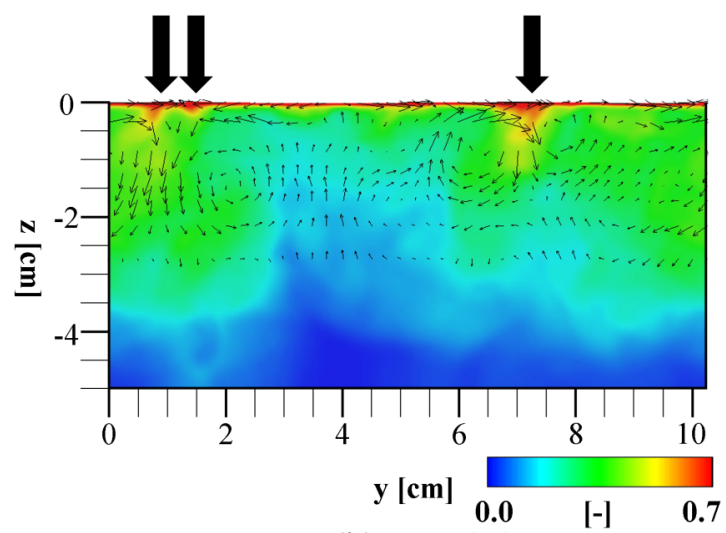

(b) $t=12.0 \mathrm{~s}$

FIG. 10. Cross-sectional ( $y-z$ plane) distributions of streamwise-averaged scalar concentration together with velocity vectors on the liquid side at (a) $t=6.0 \mathrm{~s}$ and (b) $t=12.0 \mathrm{~s}$. Scalar concentration is nondimensionalized by scalar concentration at interface $C_{\mathrm{i}}$. Nondimensional lengths are as given in Fig. 2.

\section{Scalar transfer coefficient}

Figure 11 shows the time series of the scalar coefficient $k_{\mathrm{L}}$ calculated by

$$
k_{\mathrm{L}}=\frac{F}{\Delta C}=\frac{1}{\left(C_{\mathrm{i}}-C_{\mathrm{b}}\right)} \frac{1}{A} \int_{\text {interface }} D_{\mathrm{L}} \frac{\partial C}{\partial n} d S,
$$

where $F$ is the scalar flux at the gas-liquid interface per unit area, $\Delta C$ the scalar concentration difference between the interface and bulk liquid, i.e., $\Delta C=C_{\mathrm{i}}-C_{\mathrm{b}}$ (here, $C_{\mathrm{i}}$ and $C_{\mathrm{b}}$ are the scalar concentrations of the interface and bulk liquid, respectively, and $C_{\mathrm{b}}$ is set to be zero in this study), $n$ the normal direction with respect to the gas-liquid interface, $A$ the surface area of the interface, and $D_{\mathrm{L}}$ the molecular diffusivity of scalar on the liquid side. The values of $k_{\mathrm{L}}$ at $t=6.0$ and $12.0 \mathrm{~s}$ are also listed in Table II.

From Table II and Figure 11, the value of $k_{\mathrm{L}}$ is not found to vary with time between $t=6.0$ and $12.0 \mathrm{~s}$ regardless of the change in the characteristics of the Langmuir circulations. This suggests that the turbulent eddies in the form of streamwise vortices generated on the liquid side beneath the interface mainly control the scalar transfer across the sheared wind-driven gas-liquid interface, and that the Langmuir circulations act to modulate the turbulent eddies' distribution but barely affect the value of the scalar transfer coefficient $k_{\mathrm{L}}$. Then, to quantitatively investigate the effect of Langmuir circulations on gas-liquid scalar transfer, we made a rough estimate of the ratio of the scalar transfer coefficient related to the Langmuir circulations to the total scalar transfer coefficient. The gas-liquid 


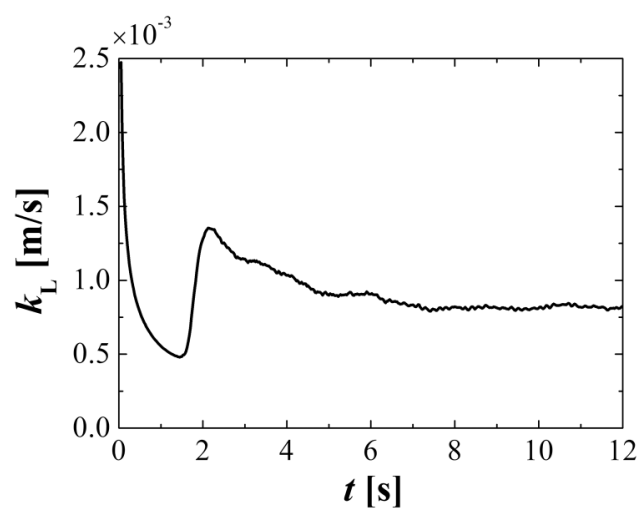

FIG. 11. Time series of scalar coefficient $k_{\mathrm{L}}$.

scalar flux $F$ can be written as

$$
F=k_{L}\left(C_{i}-C_{b}\right) \sim-\overline{w c}
$$

by the bulk model (second equation), and is almost equal to the covariance of the vertical velocity $w$ and scalar concentration $c$ (third equation) near the gas-liquid interface under the assumption that the molecular diffusion term is negligibly small compared with the total scalar flux. By decomposing the vertical velocity and scalar concentration as $w=w_{\mathrm{LC}}+w_{\mathrm{T}}$ and $c=c_{\mathrm{LC}}+c_{\mathrm{T}}$, the equation is rewritten as

$$
F \sim-\overline{w_{L C} c_{L C}}-\overline{w_{T} c_{T}},
$$

where the subscripts $L C$ and $T$ refer to "Langmuir circulations" and "turbulent eddies" contributions, respectively. Therefore, the first and second terms on the right-hand-side of Eq. (15) are the scalar fluxes due to Langmuir circulations and turbulent eddies, respectively.

Figure 12 shows the spanwise distributions of the streamwise-averaged vertical velocity and scalar concentration at $z=-2 \mathrm{~mm}$ and $t=12.0 \mathrm{~s}$. The vertical point of $z=-2 \mathrm{~mm}$ was chosen here because the half height of the significant wind waves is $H_{\mathrm{S}} / 2=1.9 \mathrm{~mm}$. Both the streamwise-averaged vertical velocity and scalar concentration fluctuate spanwise with order of the spacing of the Langmuir circulations of $D_{\text {Langmuir }}=0.0468 \mathrm{~m}$, although the spanwise fluctuation of the vertical velocity is not clear because the wave length for the turbulent eddies is smaller than $D_{\text {Langmuir }}=0.0468 \mathrm{~m}$. In separating the vertical velocity and scalar concentration into contributions due to Langmuir circulations and turbulent eddies, we employed two decomposition methods (1) the low-pass filter and (2) the empirical mode decomposition (EMD), used in Huang et al. ${ }^{35}$ and Tsai et al..$^{25}$ The solid (black) curve in Figure 12(a) shows the original vertical velocity. The dashed (red) curve shows the vertical velocity $w_{\mathrm{LP}}$ low-pass filtered with the threshold wave-number same as that of the Langmuir circulations $\left(k_{\text {Langmuir }}=134 \mathrm{~m}^{-1}\right)$. The dotted (blue) and dashed-dotted (green) curves show the vertical velocities $w_{\mathrm{EMD}, \mathrm{m}}$ calculated by the intrinsic mode functions $I M F_{\mathrm{i}}$

TABLE II. Scalar transfer coefficient and surface divergence. $t$ : elapsed time, $U_{\infty}$ : free stream wind speed, $k_{\mathrm{L} 600}$ : liquid-side scalar transfer coefficient, $\beta_{\mathrm{RMS} 1}, \beta_{\mathrm{RMS} 2}, \beta_{\mathrm{RMS} 3}$ : root-mean-square value of surface divergence with $V S=0.5,1.0$, and $1.5 \mathrm{~mm}$.

\begin{tabular}{rccccc}
\hline \hline$t(\mathrm{~s})$ & $\begin{array}{c}U_{\infty} \\
(\mathrm{m} / \mathrm{s})\end{array}$ & $\begin{array}{c}k_{\mathrm{L} 600}\left(10^{-5}\right) \\
(\mathrm{m} / \mathrm{s})\end{array}$ & $\begin{array}{c}\beta_{\text {RMS1 }} \\
\left(\mathrm{s}^{-1}\right)\end{array}$ & $\begin{array}{c}\beta_{\text {RMS2 }} \\
\left(\mathrm{s}^{-1}\right)\end{array}$ & $\begin{array}{c}\beta_{\text {RMS3 }} \\
\left(\mathrm{s}^{-1}\right)\end{array}$ \\
\hline 6.0 & 4.30 & 3.68 & 42.2 & 36.5 & 33.4 \\
12.0 & 3.48 & 3.36 & 40.4 & 33.6 & 31.2 \\
\hline \hline
\end{tabular}



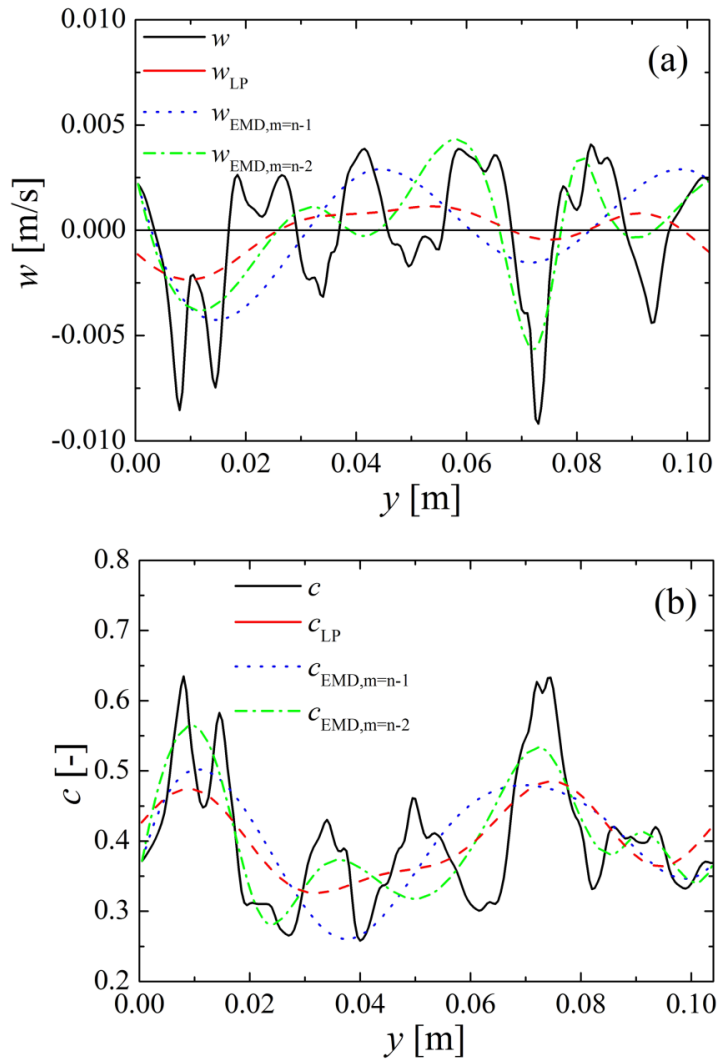

FIG. 12. Spanwise distributions of (a) streamwise-averaged vertical velocity and (b) scalar concentration at $z=-2 \mathrm{~mm}$ and $t=12.0 \mathrm{~s}$. Dashed (red) curves show $w$ and $c$ low-pass filtered with a threshold wave-number which is the same as that of the Langmuir circulations $\left(k_{\text {Langmuir }}=134 \mathrm{~m}^{-1}\right.$ ), dotted (blue) and dashed-dotted (green) curves show $w$ and $c$ calculated by the empirical mode decomposition with $\mathrm{m}=\mathrm{n}-1$ and $\mathrm{m}=\mathrm{n}-2$, respectively.

and the residue $r_{\mathrm{n}}$ in the EMD algorithm shown as

$$
w_{E M D, m} \sim \sum_{i=m}^{n} I M F_{i}+r_{n},
$$

where the relations $\mathrm{m}=\mathrm{n}-1$ and $\mathrm{m}=\mathrm{n}-2$ are used to obtain the dotted (blue) and dashed-dotted (green) curves. The curves in Figure $12(\mathrm{~b})$ are the scalar concentrations $\left(c_{\mathrm{LP}}, c_{\mathrm{EMD}, \mathrm{m}}\right)$ calculated in the same manner as in Figure 12(a). We then estimated the three scalar fluxes $\left(F_{\mathrm{LC} 1}, F_{\mathrm{LC} 2}, F_{\mathrm{LC} 3}\right)$ using the following assumptions:

$$
\begin{aligned}
& F_{L C 1} \sim-\overline{w_{L C 1} c_{L C 1}}=-\overline{w_{L P} c_{L P}}, \\
& F_{L C 2} \sim-\overline{w_{L C 2} c_{L C 2}}=-\overline{w_{E M D, n-1} c_{E M D, n-1}}, \\
& F_{L C 3} \sim-\overline{w_{L C 3} c_{L C 3}}=-\overline{w_{E M D, n-2} c_{E M D, n-2}},
\end{aligned}
$$

and the scalar fluxes $\left(F_{\mathrm{T} 1}, F_{\mathrm{T} 2}, F_{\mathrm{T} 3}\right)$ were also estimated as differences between the total scalar flux and each scalar flux $F_{\mathrm{LC} 1}, F_{\mathrm{LC} 2}$, and $F_{\mathrm{LC} 3}$, respectively. The ratios $F_{\mathrm{LC} 1} / F_{\mathrm{T} 1}, F_{\mathrm{LC} 2} / F_{\mathrm{T} 2}$, and $F_{\mathrm{LC} 2} / F_{\mathrm{T} 2}$ were $2.4 \%, 12.5 \%$, and $13.2 \%$, respectively. This shows that the effect of the Langmuir circulations on the gas-liquid scalar transfer is relatively small and the gas-liquid scalar transfer is mainly controlled by turbulent eddies near the gas-liquid interface on the liquid side.

Very recently, Sullivan et al. ${ }^{36}$ reported that the Langmuir circulations are seen not only at low and moderate wind speeds but also at extremely high wind speeds of $U_{10}>35 \mathrm{~m} / \mathrm{s}$ under tropical cyclones. Our results also suggest that such Langmuir circulations under tropical cyclones possibly do not affect the value of the scalar transfer coefficient $k_{\mathrm{L}}$ (e.g., McNeil and D'Asaro; ${ }^{3}$ Iwano et al. ${ }^{10}$ ) because turbulence becomes large as the wind speed increases. 
Presently predicted $k_{\mathrm{L}}$ was compared to previously predicted $k_{\mathrm{L}}$ (Komori et al. ${ }^{17}$ ) and measured $k_{\mathrm{L}}$ (Iwano et al.; ${ }^{10}$ Turney et al. $;^{37}$ Krall and Jähne, ${ }^{38}$ ) normalized using

$$
\begin{aligned}
& k_{L}{ }^{*}=\frac{k_{L 600}}{u^{*}}, \\
& k_{L}{ }^{+}=\frac{k_{L 600}}{U_{\infty}},
\end{aligned}
$$

where $U_{\infty}$ is the uniform wind velocity and $k_{\mathrm{L}}$ normalized using the assumption (Jähne et al. ${ }^{5}$ )

$$
k_{L 600}=k_{L}\left(\frac{S c_{600}}{S c}\right)^{-0.5} .
$$

Here, $S c$ is the Schmidt number of the scalar and $S c_{600}$ is the Schmidt number having the value 600. The previous values of the normalized scalar transfer coefficients were $k_{\mathrm{L}}{ }^{*}=1.4 \times 10^{-4}$

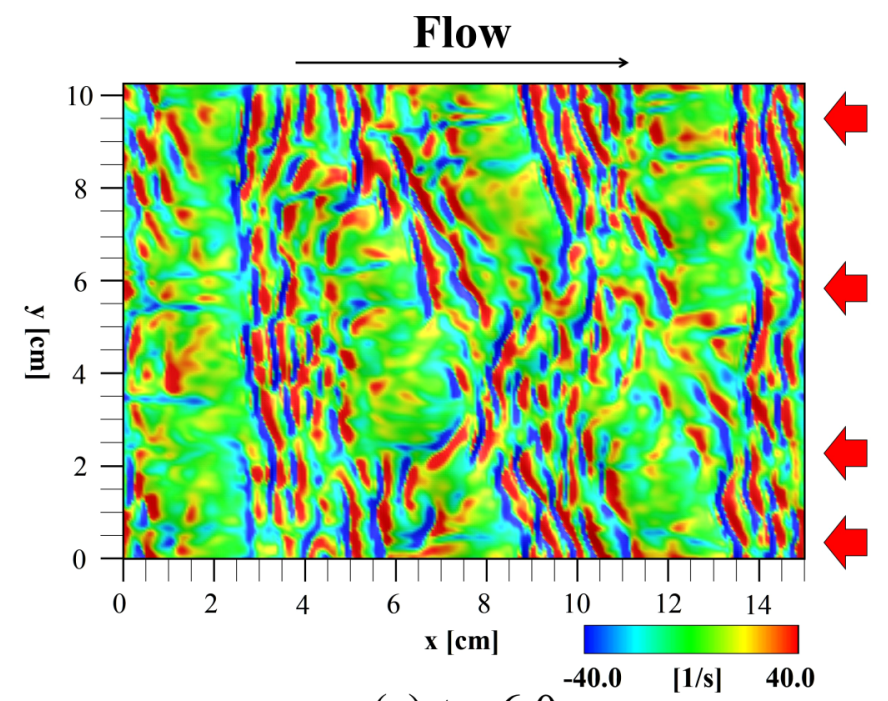

(a) $t=6.0 \mathrm{~s}$

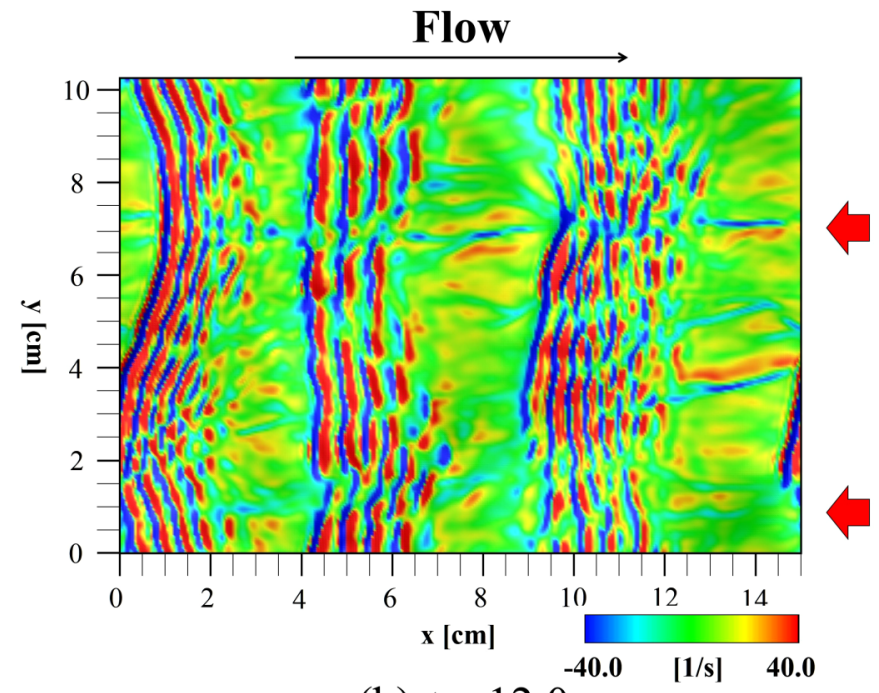

(b) $t=12.0 \mathrm{~s}$

FIG. 13. Distributions of instantaneous surface divergence at (a) $t=6.0 \mathrm{~s}$ and (b) $t=12.0 \mathrm{~s}$. The red and blue areas indicate positive and negative values, that is, the locations where the liquid surface diverges with vertical upward flow and converges with vertical downward flow, respectively. Arrows show streak locations. Nondimensional lengths are as given in Fig. 2. 
$-2.0 \times 10^{-4}$ and $k_{\mathrm{L}}{ }^{+}=0.6 \times 10^{-5}-1.0 \times 10^{-5}$ within the range of the gas-side friction velocity $u_{\mathrm{a}}{ }^{*}$ $=0.2-0.32 \mathrm{~m} / \mathrm{s}$. With the present values of $k_{\mathrm{L}}{ }^{*}=1.3 \times 10^{-4}$ and ${k_{\mathrm{L}}}^{+}=0.9 \times 10^{-5}$ at $u_{\mathrm{a}}{ }^{*} \sim 0.27 \mathrm{~m} / \mathrm{s}$, it is clear that $k_{\mathrm{L}}$ almost corresponds to the previously predicted and measured $k_{\mathrm{L}}$ (Komori et al.; ${ }^{17}$ Iwano et al. $;^{10}$ Turney et al. $;{ }^{37}$ Krall and Jähne ${ }^{38}$ ).

\section{Surface divergence model}

Since the surface divergence model is one of the suitable models for estimating gas-liquid scalar transfer coefficients (e.g., McCready et al. $;^{39}$ Banerjee et $a l .{ }^{40}$ ), it was used to calculate the surface divergences $\beta$

$$
\beta=-\left.\frac{\partial w^{\prime}}{\partial \hat{z}}\right|_{\hat{z}=0}=\left.\left(\frac{\partial u^{\prime}}{\partial \hat{x}}+\frac{\partial v^{\prime}}{\partial \hat{y}}\right)\right|_{\hat{z}=0} .
$$

Here, $\hat{x}$ and $\hat{y}$ are the tangential directions and $\hat{z}$ is the normal direction. The $u^{\prime}$ and $v^{\prime}$ are the tangential fluctuating velocities in the streamwise and spanwise directions and $w^{\prime}$ is the normal fluctuating velocity. The spacing of the velocity vectors $V S$ is $0.5 \mathrm{~mm}$, as that is the minimum horizontal grid size. Figure 13 shows the distribution of the surface divergence at $t=6.0$ and $12.0 \mathrm{~s}$. The red and blue areas show positive and negative values, that is, the locations where the divergence/convergence of the liquid surface due to the vertical upward/downward flow occurs. At $t=6.0$ and $12.0 \mathrm{~s}$, many pairings of areas for divergence and convergence, which are elongated in the spanwise direction, exist at the liquid surface because of capillary waves (so-called ripples) downstream from the wave crests. Moreover, there are streamwise streaks, and the locations of the streaks weakly correspond to that of Langmuir circulations indicated by arrows in Figure 13. To evaluate the surface divergence model for gas-liquid scalar transfer, the root-mean-square values of the surface divergence $\beta_{\text {RMS1 }}$ were calculated and are listed in Table II. The values of $\beta_{\text {RMS2 }}$ and $\beta_{\mathrm{RMS} 3}$ were also calculated with the conditions of velocity-vector spacing $V S=1.0$ and $1.5 \mathrm{~mm}$, respectively, and are included in Table II, where velocity vectors for spacing $V S=1.0$ and $1.5 \mathrm{~mm}$ were obtained from the original velocity vectors of spacing $V S=0.5 \mathrm{~mm}$ by box filtering. Figure 14 shows the time series of the RMS values of the surface divergence. The RMS values of the surface divergence take almost constant value between $t=6.0$ and $12.0 \mathrm{~s}$. Figure 15 shows the relationship between the measured values of the liquid-side scalar transfer coefficient $k_{\mathrm{L}}$ and the values $k_{\mathrm{Lmodel}}$ proposed by McCready et al..$^{39}$ and estimated from the surface divergence model

$$
k_{\text {Lmodel }}=0.25 \sqrt{\beta_{R M S} D_{L}},
$$

where $D_{\mathrm{L}}$ is the molecular diffusivity of scalar on the liquid side. We can see good agreement between these measured and estimated values in both present and previous studies (Turney et al. ${ }^{37}$ ).

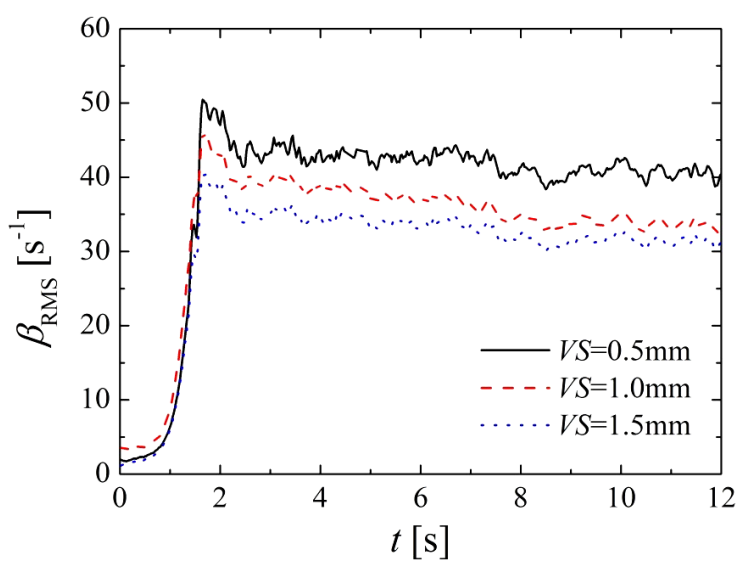

FIG. 14. Time series of RMS values of surface divergence under conditions of velocity-vector spacing $V S=0.5,1.0$, and $1.5 \mathrm{~mm}$. 


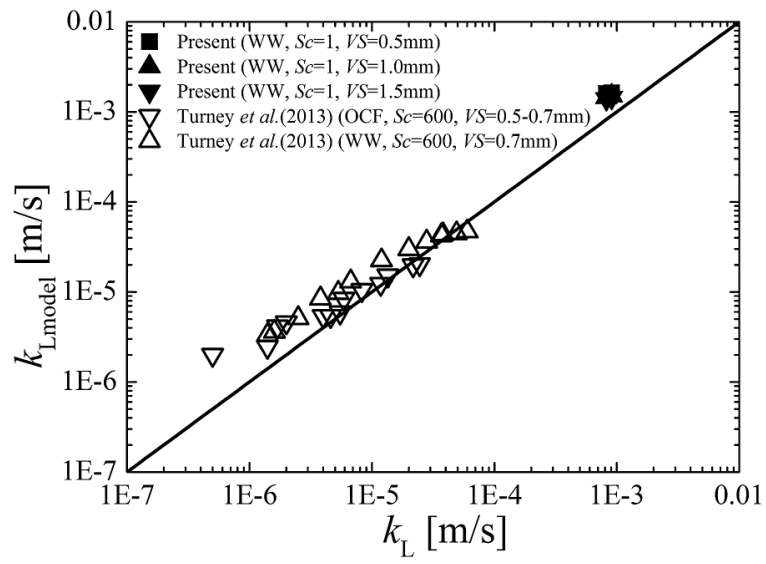

FIG. 15. Relationship between measured and estimated values of the liquid-side scalar transfer coefficient. The values of $k_{\text {Lmodel }}$ are estimated using Eq. (24). WW: wind-sheared water surface; OCF: open-channel water surface.

This suggests that surface divergence could be a useful parameter even for instances when Langmuir circulations are present.

\section{CONCLUSIONS}

The effects of turbulent eddies and Langmuir circulations in liquid flow on scalar transfer across a sheared wind-driven gas-liquid interface were investigated by means of a DNS of a gas-liquid two-phase turbulent flow with a wind-driven nonbreaking wavy interface. The main results obtained in this study are summarized as follows:

(1) The Langmuir circulations are generated on the liquid side below the sheared wind-driven gas-liquid interface. The trends in the Langmuir circulations accompanying streamwise surface currents and downward flows on the liquid side correspond well to those in previous analytical and experimental studies.

(2) The marker particles on the gas-liquid interface, the turbulent eddies in the form of streamwise vortices on the liquid side (i.e., the typical horseshoe vortices associated with bursting motions), and the low scalar flux lines on the gas-liquid interface induced by the turbulent eddies on the liquid side tend to locally concentrate on the regions along the downward flows caused by the Langmuir circulations.

(3) The cross-sectional ( $y-z$ plane) distributions of both the instantaneous and streamwiseaveraged scalar concentration on the liquid side below the gas-liquid interface suggest that the turbulent eddies generated on the liquid side beneath the interface mainly control the scalar transfer across the sheared wind-driven gas-liquid interface, whereas the Langmuir circulations act to modulate the turbulent eddies' distribution but hardly affect the value of the liquid-side scalar transfer coefficient. In order to roughly estimate the liquid-side scalar transfer coefficient, the surface divergence could be a useful parameter even in the existence of the Langmuir circulations.

\section{ACKNOWLEDGMENTS}

The authors are grateful to Professor Wu-ting Tsai for useful discussion. They also would like to thank Dr. Keigo Matsuda of ESC, JAMSTEC and Mr. Atsushi Kimura for their help in developing the code and data visualization. This research was supported by Ministry of Education, Science, Sports, and Culture Grant-in-Aid (Nos. 24360069 and 25249013). The computations were performed by super computers of Earth Simulator Center, JAMSTEC and National Institute for Environmental Studies, Center for Global Environmental Research. 
${ }^{1}$ R. Wanninkhof and W. R. McGillis, "A cubic relationship between air-sea $\mathrm{CO}_{2}$ exchange and wind speed," Geophys. Res. Lett. 26, 1889-1892, doi:10.1029/1999GL900363 (1999).

${ }^{2}$ W. R. McGillis, J. B. Edson, J. E. Hare, and C. W. Fairall, “Direct covariance air-sea $\mathrm{CO}_{2}$ fluxes,” J. Geophys. Res. 106(C8), 16729-16745, doi:10.1029/2000JC000506 (2001).

${ }^{3}$ C. McNeil and E. D'Asaro, "Parameterization of air-sea gas fluxes at extreme wind speeds," J. Mar. Syst. 66, 110-121 (2007).

${ }^{4}$ B. Jähne, K. O. Münnich, and U. Siegenthaler, "Measurements of gas exchange and momentum transfer in a circular wind-water tunnel," Tellus 31, 321-329 (1979).

${ }^{5}$ B. Jähne, K. O. Münnich, R. Bösinger, A. Dutzi, W. Huber, and P. Libner, "On the parameters influencing air-water gas exchange,” J. Geophys. Res. 92(C2), 1937-1949, doi:10.1029/jc092ic02p01937 (1987).

${ }^{6}$ B. Jähne, T. Wais, L. Memery, G. Caulliez, L. Merlivat, K. O. Münnich, and M. Coantic, "HE and RN gas exchange experiments in the large wind-wave facility of IMST," J. Geophys. Res. 90, 11989-11998, doi:10.1029/jc090ic06p11989 (1985).

${ }^{7}$ R. Wanninkhof, "Relationship between wind speed and gas exchange over the ocean," J. Geophys. Res. 97(C5), 7373-7382, doi:10.1029/92jc00188 (1992).

${ }^{8}$ S. Komori, R. Nagaosa, and Y. Murakami, "Turbulence structure and mass transfer across a sheared air-water interface in wind-driven turbulence,” J. Fluid Mech. 249, 161-183 (1993).

${ }^{9}$ S. Komori, R. Kurose, N. Takagaki, S. Ohtsubo, K. Iwano, K. Handa, and S. Shimada, "Sensible and latent heat transfer across the air-water interface wind-driven turbulence," in Gas Transfer at Water Surfaces 2010, edited by S. Komori, W McGillis, and R. Kurose (Kyoto University Press, Kyoto, 2011), pp. 78-89.

${ }^{10}$ K. Iwano, N. Takagaki, R. Kurose, and S. Komori, "Mass transfer velocity across the breaking air-water interface at extremely high wind speeds," Tellus B 65, 21341 (2013).

${ }^{11}$ T. Kunugi, S. Satake, and Y. Ose, "Direct numerical simulation of carbon-dioxide gas absorption caused by turbulent free surface flow," Int. J. Heat Fluid Flow 22, 245-251 (2001).

${ }^{12}$ D. Lakehal, M. Fulgosi, G. Yadigaroglu, and S. Banerjee, "Direct numerical simulation of turbulent heat transfer across a mobile, sheared gas-liquid interface," J. Heat Transfer 125, 1129-1139 (2003).

${ }^{13}$ D. Lakehal, M. Fulgosi, S. Banerjee, and G. Yadigaroglu, "Turbulence and heat exchange in condensing vapor-liquid flow," Phys. Fluids 20, 065101 (2008).

${ }^{14}$ D. Lakehal, M. Fulgosi, and G. Yadigaroglu, "Direct numerical simulation of condensing stratified flow," J. Heat Transfer 130, 021501 (2008).

${ }^{15}$ S. Banerjee, D. Lakehal, and M. Fulgosi, "Surface divergence models for scalar exchange between turbulent streams," Int. J. Multiphase Flow 30, 963-977 (2004).

${ }^{16}$ S. Banerjee, "Modeling of interphase turbulent transport processes," Ind. Eng. Chem. Res. 46, 3063-3068 (2007).

${ }^{17}$ S. Komori, R. Kurose, K. Iwano, T. Ukai, and N. Suzuki, "Direct numerical simulation of wind-driven turbulence and scalar transfer at sheared gas-liquid interfaces," J. Turbulence 11, N32 (2010).

18 A. D. D. Craik and S. Leibovich, "A rational model for Langmuir circulations," J. Fluid Mech. 73, 401-426 (1976).

${ }^{19}$ S. Leibovich, "The form and dynamics of Langmuir circulations," Annu. Rev. Fluid Mech. 15, 391-427 (1983).

${ }^{20}$ S. A. Thorpe, "Langmuir circulation," Annu. Rev. Fluid Mech. 36, 55-79 (2004).

${ }^{21}$ J. McWilliams, P. Sullivan, and C. Moeng, "Langmuir turbulence in the ocean,” J. Fluid Mech. 334, 1-30 (1997).

${ }^{22}$ P. P. Sullivan and J. C. McWilliams, "Dynamics of winds and currents coupled to surface waves," Annu. Rev. Fluid Mech. 42, 19-42 (2010).

${ }^{23}$ C. S. Garbe, A. Rutgersson, J. Boutin, B. Delille, C. W. Fairall, N. Gruber, J. Hare, D. Ho, M. Johnson, G. de Leeuw, P. Nightingale, H. Pettersson, J. Piskozub, E. Sahlee, W. Tsai, B. Ward, D. K. Woolf, and C. Zappa, "Transfer across the air-sea interface," Ocean-Atmosphere Interactions of Gases and Particles, edited by P. S. Liss and M. T. Johnson (Springer, Berlin, 2014), pp. 55-112.

${ }^{24}$ W. K. Melville, R. Shear, and F. Veron, "Laboratory measurements of the generation and evolution of Langmuir circulations," J. Fluid Mech. 364, 31-58 (1998).

${ }^{25}$ W. T. Tsai, S. M. Chen, G. H. Lu, and C. S. Garbe, "Characteristics of interfacial signatures on a wind-driven gravity-capillary wave,” J. Geophys. Res.: Oceans 118, 1715-1735, doi:10.1002/jgrc.20145 (2013).

${ }^{26}$ S. Komori, R. Nagaosa, Y. Murakami, S. Chiba, K. Ishii, and K. Kuwahara, "Direct numerical simulation of threedimensional open-channel flow with zero-shear gas-liquid interface,” Phys. Fluids A 5, 115-125 (1993).

${ }^{27}$ M. Fulgosi, D. Lakehal, S. Banerjee, and V. De Angelis, "Direct numerical simulation of turbulence in a sheared air-water flow with a deformable interface," J. Fluid Mech. 482, 319-345 (2003).

${ }^{28}$ M.-Y. Lin, C.-H. Moeng, W.-T. Tsai, P. P. Sullivan, and S. E. Belcher, "Direct numerical simulation of wind-wave generation processes," J. Fluid Mech. 616, 1-30 (2008).

${ }^{29}$ F. H. Harlow and J. E. Welch, "Numerical calculation of time-dependent viscous incompressible flow of fluid with free surface," Phys. Fluids 8, 2182-2189 (1965).

${ }^{30}$ N. Takagaki, S. Komori, N. Suzuki, K. Iwano, T. Kuramoto, S. Shimada, R. Kurose, and K. Takahashi, "Strong correlation between the drag coefficient and the shape of the wind sea spectrum over a broad range of wind," Geophys. Res. Lett. 39, L23604, doi:10.1029/2012GL053988 (2012).

${ }^{31}$ Y. Toba, "Local balance in the air-sea boundary processes," J. Oceanogr. Soc. Jpn. 28, 109-120 (1972)

${ }^{32}$ S. Leibovich and S. Paolucci, "The instability of the ocean to Langmuir circulations," J. Fluid Mech. 102, 141-167 (1981).

${ }^{33}$ J. Schnieders, S. Garbe, W. L. Peirson, G. B. Smith, and C. J. Zappa, "Analyzing the footprints of near surface aqueous turbulence: An image processing-based approach,” J. Geophys. Res.: Oceans 118, 1272-1286, doi:10.1002/jgrc.20102 (2013).

${ }^{34}$ C. R. Smith and S. P. Metzler, "The characteristics of low speed streaks in the near-wall region," J. Fluid Mech. 129, 27-54 (1983).

${ }^{35}$ N. E. Huang, Z. Shen, S. R. Long, M. C. Wu, H. H. Shih, Q. Zheng, N. C. Tung, and H. H. Liu, "The empirical mode decomposition and the Hilbert spectrum for nonlinear and non-stationary time series analysis," Proc. R. Soc. London, Ser A 454, 903-995 (1998). 
${ }^{36}$ P. P. Sullivan, L. Romero, J. McWilliams, and W. K. Melville, "Transient evolution of Langmuir turbulence in ocean boundary layers driven by hurricane winds and waves," J. Phys. Oceanogr. 42, 1959-1980 (2012).

${ }^{37}$ D. E. Turney and S. Banerjee, "Air-water gas transfer and near-surface motions," J. Fluid Mech. 733, 588-624 (2013).

${ }^{38}$ K. E. Krall and B. Jähne, "First laboratory study of air-sea gas exchange at hurricane wind speeds," Ocean Sci. 10, 257-265 (2014).

${ }^{39}$ M. J. McCready, E. Vassilliadou, and T. J. Hanratty, “Computer simulation of turbulent mass transfer at a mobile interface," AIChE J. 32, 1108-1115 (1986)

${ }^{40}$ S. Banerjee, D. Lakehal, and M. Fulgosi, "Surface divergence models for scalar exchange between turbulent streams," Int. J. Multiphase Flow 30, 963-977 (2004). 